\title{
Preparation and Characterization of Polystyrene Microspheres Surface-Modified with Glucoside Moieties
}

\author{
Kazuo SugiYama* and Terumasa OKu \\ Department of Industrial Chemistry, Faculty of Engineering, Kinki University, \\ Takaya, Higashihiroshima, Hiroshima 729-17, Japan
}

(Received September 16, 1994)

\begin{abstract}
The emulsifier-free emulsion copolymerization of 2-(glucosyloxy) ethyl methacrylate (GEMA) and styrene (St), yielded a series of copolymer microspheres [poly(GEMA-coSt) microspheres] with varying content of the GEMA moiety. 2-[(2-Ethylphosphatoethyl)dimethylammonio] ethyl 4,4'-azobis(4-cyanovalerate) (EAP-501) and potassium persulfate (KPS) were used as initiators. From the copolymerization of GEMA and St it was found that the initial rate of polymerization of St increased in the presence of a small amount of GEMA. Poly(GEMA-co-St) microspheres showed unimodal distribution of particle sizes with $240-440 \mathrm{~nm}$, which depended on mol\% of GEMA to St in feed and species of initiator. The $\zeta$-potential of the particles was nearly zero $(0 \sim-9 \mathrm{mV})$ and $-68 \sim-99 \mathrm{mV}$ for poly(GEMA-co-St) microspheres produced by EAP-501 and KPS, respectively. From XPS measurements the GEMA moiety was found located on the surface of the particles. Poly(GEMA-co-St) microspheres with a hydrophilic surface suppressed the adsorption of albumin ( $\mathrm{Alb}$ ) and globulin (Glo), less than the poly(St) microspheres as the control. It was concluded that the suppression of adsorption of a protein onto poly(GEMA-co-St) microspheres is dependent on hydrophilicity due to the GEMA moiety and ammonium phosphate group derived from EAP-501 on the surface of particles.

KEY WORDS Emulsion Copolymerization / Glucoside Monomer / Surface-Modified Polystyrene Microsphere / XPS / Albumin / Globulin /

Adsorption /
\end{abstract}

A variety of concepts have been described to improve the surface of synthetic polymers, through use of a phosphorylcholine moiety, which exists on the extracellular surface of the lipid bilayer, in connection with biocompatible applications and other purposes. ${ }^{1-4}$ The thrombo-resistance of vinyl polymers can be improved by incorporating the 2-methacryloyloxyethyl phosphorylcholine (MPC) moiety as a comonomer in the solution copolymerization. ${ }^{5-8}$ In previous papers, the authors reported that MPC as well as 2-acryloyloxyethyl phosphorylcholine (APC) copolymerize with various vinyl monomers in soap-free emulsion polymerization to yield copolymer microspheres, on whose surfaces the phos-

\footnotetext{
* To whom correspondence should be addressed.
}

phorylcholine moiety is concentrated. ${ }^{9,10}$ The emulsion polymerization of styrene (St) initiated with an amphiphilic azo-initiator, 2[(2-ethylphosphatoethyl)dimethylammonio]ethyl 4,4'-azobis (4-cyanovalerate) (EAP-501), gives poly(St) microspheres whose surfaces are also modified with an analogous structure to the polar head group of phosphatidyl choline. ${ }^{11}$ These polymer microspheres were found to reduce protein adsorption on the surface of the particles.

On the other hand, copolymers carrying pendant saccharide moieties were prepared as the pharmacological and biomedical materials because oligosaccharides, which protrude from the surface of cell membranes, function as 
recognition markers for enzymes, proteins, and others. ${ }^{12-16}$ Since Kitazawa et al. ${ }^{17}$ recently synthesized the saccharide-bound monomers, for instance, 2-(glucosyloxy)ethyl methacrylate (GEMA) by a one-step process without any protective groups, the GEMA unit containing copolymers are prepared and characterized as the pharmacological and biomedical materials. ${ }^{18,19}$

In the course of our study on the functionalized polymer microspheres, $, 9,10,20,21$ our interest was directed to the immobilization of both the phosphorylcholine analogous and monosaccharide moieties on the surface of polymer microspheres to produce a surface similar to a biomembrane. The present article describes on the soap-free emulsion copolymerization of GEMA and St initiated with an amphiphilic EAP-501. The characterization as well as biomedical applications of the resultant copolymer microspheres are also discussed.

\section{EXPERIMENTAL}

\section{Reagents}

Fifty percent aqueous solution of glucoside monomer (GEMA) was kindly supplied by Research Laboratory, Nippon Fine Chemical Co., Ltd. and used as obtained. EAP-501, mp (dec.) $97^{\circ} \mathrm{C}$ and $\lambda_{\max }\left(\mathrm{H}_{2} \mathrm{O}\right) 346 \mathrm{~nm}$, was prepared by the method described previously. ${ }^{11} \mathrm{St}$ was washed with aqueous $\mathrm{Na}_{2} \mathrm{~S}_{2} \mathrm{O}_{3}$, water and aqueous $\mathrm{NaOH}$, then with water again, dried over $\mathrm{MgSO}_{4}$ and distilled under reduced pressure of nitrogen at $40^{\circ} \mathrm{C}$. Potassium persulfate (KPS) was recrystallized from water. Crystallized and lyophilized bovine serum albumin (Alb) and human serum $\gamma$-globulin (Glo) were obtained from Sigma Chemical Co. and Wako Pure Chemicals, respectively and used without further purification. Distilled deionized water was used throughout the experiments.

\section{Emulsion Copolymerization}

Surface-modified polystyrene microspheres with a glucoside moiety, poly(GEMA-co-St) microspheres, were prepared by soap-free emulsion polymerization. Into a $0.5-\mathrm{dm}^{3}$ separable round-bottomed flask, equipped with a mechanical stirred, condenser, and $\mathrm{N}_{2}$ inlet tube, were placed known amounts of St and GEMA in $0.24 \mathrm{dm}^{3}$ of water. After being kept at $70^{\circ} \mathrm{C}$ over a period of $0.5 \mathrm{~h}$, the required amount of EAP-501 (or KPS) aqueous solution $\left(0.01 \mathrm{dm}^{3}\right)$ was added at once and the mixture was stirred at a spinning rate of $350 \mathrm{rpm}$ for another $12 \mathrm{~h}$. For estimation of the kinetics of the copolymerization, $2 \mathrm{ml}$ aliquots of the emulsion sample obtained from the stirred emulsion at fixed time intervals were poured into a large amount of methanol to precipitate the polymer. The conversion was calculated from the weight of the dry polymer obtained. Poly(St) microspheres were also prepared as the control. The polymer microspheres used for adsorption experiments were purified as follows. The polymer microspheres were filtrated through a glass filter (Type: 17G2) to remove coarse particles and coagulum. The coagulum was filtered, dried, and weighed. The filtrate was centrifuged, decanted and redispersed in water. After repeating this procedure three times, the polymer microspheres were finally purified by treatment with the mixture of cation- and anion- exchange resins (PK-212 and PA-312) purchased from Mitsubishi Chemical Industries, Ltd. The water soluble polymer was obtained as follows. The water layer after removing polymer microspheres by centrifugation was poured into a large amount of 2-propanol to precipitate the polymer.

\section{Measurements of Particle Size}

Particle size of polymer microspheres was determined by scanning electron microscopy (SEM) at $25 \mathrm{kV}$ with a Hitachi S-2150: the particle size was estimated by comparing SEM with a polystyrene latex standard (DowChemicals, Uniform particles, $\phi 474 \mathrm{~nm}$, Lot No. $1 \times 90$ ). Size distribution of the particles 
was measured with a Pacific Scientific NICOMP 370.

\section{$X$-Ray Photoelectron Spectroscopy (XPS)}

The surface of polymer microspheres was analyzed by XPS using a Shimadzu ESCA 750. The ratio of the number of atoms for oxygen to carbon was obtained based on relative sensitivity factors, 2.85 for $\mathrm{O}_{1 \mathrm{~s}} / \mathrm{C}_{1 \mathrm{~s}}$. The spectra of $\mathrm{C}_{1 \mathrm{~s}}$ and $\mathrm{O}_{1 \mathrm{~s}}$ were measured for 3 scans.

\section{Measurements of $\zeta$-Potentials}

The $\zeta$-potential of polymer microspheres was measured at $\mathrm{pH} 5.6$ at 0.001 of ionic strength adjusted with $\mathrm{NaCl}$ at ambient temperature by the microelectrophoresis method using a Mitamura Riken microelectrophoresis apparatus with an Olympus microscope.

\section{Adsorption Procedure}

Interactions between the polymer microspheres and protein were measured at 0.01 of ionic strength adjusted with $\mathrm{NaCl}$ at $\mathrm{pH} 5.6$ and $\mathrm{pH} 6.7$ for Alb and Glo, respectively. A mixture of a known concentration of protein aqueous solution and $40 \mathrm{~m}^{2} 1^{-1}$ of polymer microspheres was equilibrated at $25^{\circ} \mathrm{C}$ for $2 \mathrm{~h}$, followed by centrifugation at $12500 \mathrm{rpm}$ for $15 \mathrm{~min}$. The amount of a protein adsorbed onto the polymer microspheres was determined by the Lowry method. ${ }^{22}$ The amount of protein adsorbed was calculated from the content of free protein in water, measuring absorbance at $750 \mathrm{~nm}$ by UV measurements with a Shimadzu UV-160A spectrophotometer.

\section{RESULTS AND DISCUSSION}

\section{Emulsifier Free Emulsion Copolymerization of} GEMA with $S t$

The structures of the compounds used in this work are shown in Figure 1.

The emulsion copolymerization of GEMA with St was carried out in the absence of emulsifier at $70^{\circ} \mathrm{C}$. The initiators used were an inorganic KPS and organic azo-compound, EAP-501 having an analogous structure to the polar group of phospholipid, synthesized by us. The rate of polymerization is considerably influenced by the conditions as shown in Figure 2. The figure shows greatly enhanced rates of polymerization of $\mathrm{St}$ at an earlier stage after a short induction period when GEMA was used as a comonomer. This means that a larger number of water-soluble oligomeric radicals are produced, which reach a certain critical size and begin to form particles, when GEMA is present. At the same time, the limiting yields were observed for poly(GEMA-co-St) microspheres. The water soluble polymers propagated out of the monomer-swollen micelles and particles or monomer droplets may account for this limiting conversion as mentioned below.

Poly(GEMA-co-St) microspheres were also
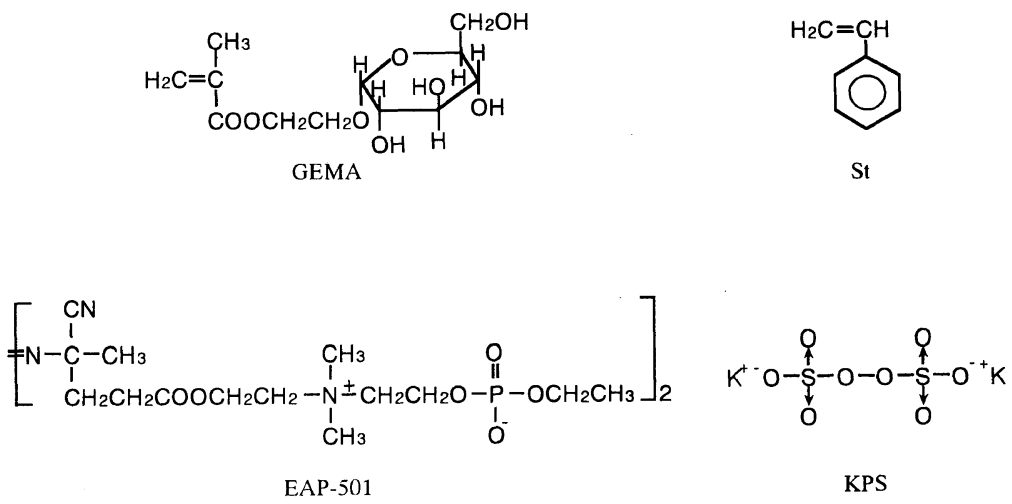

Figure 1. Structures of monomers and initiators. 


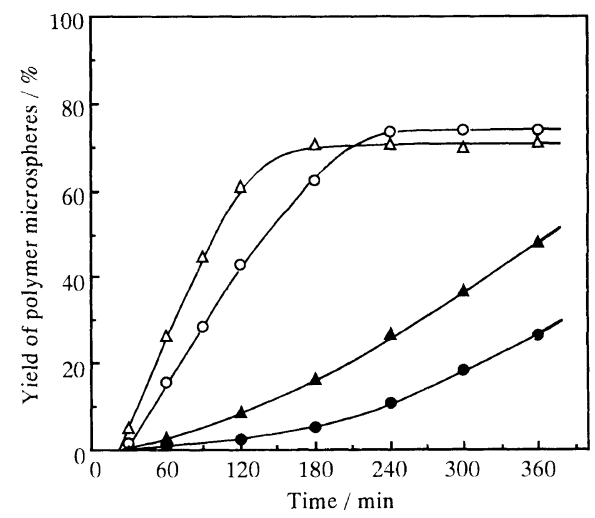

Figure 2. Polymer microspheres-time curves for the sorp free-emulsion polymerization of GEMA and St at $70^{\circ} \mathrm{C}$. $\mathrm{St}, 240 \mathrm{mmol}$; water, $0.25 \mathrm{dm}^{3}$; speed of agitation, $350 \mathrm{rpm}$. O, GEMA, $12 \mathrm{mmol}$; EAP-501, $0.25 \mathrm{mmol} ; \triangle$, GEMA, $12 \mathrm{mmol}$; KPS, $0.25 \mathrm{mmol}$; , EAP-501; $1.80 \mathrm{mmol}$; KPS; $0.5 \mathrm{mmol}$.

prepared by the batch emulsion copolymerization of GEMA and St initiated with EAP-501 in the absence of emulsifier under a nitrogen atmosphere at $70^{\circ} \mathrm{C}$, varying the $\mathrm{mol} \%$ of GEMA to St monomer $(f)$ in feed from $f=0$ to $f=50$. The results of copolymerization are given in Table I, together with those of the copolymer microspheres $(f=0-5)$ produced by KPS. In the case of run 7, the copolymerization gave poly(GEMA-co-St) microspheres in $79.6 \%$ yield and the water soluble polymer (see EXPERIMENTAL) in $15 \%$ yield without a coagulum. Therefore, in other cases, the yield of poly(GEMA-co-St) microspheres reached the maximum at around $80 \%$ because the water soluble polymer rich in the GEMA unit was produced in addition to the coagulum.

\section{SEM Measurements and Particle Size Distribu- tion}

Figure 3 shows the SEM micrographs of poly(GEMA-co-St) microspheres with $f=1$ 10 produced by EAP-501, together with that of $\operatorname{poly}(\mathrm{St})$ microspheres with $f=0$. The SEM micrographs similar to those as shown in Figure 3 were taken for the poly(GEMA-co-St) microspheres produced by KPS. The particle size distribution of poly(GEMA-co-St) microspheres was also measured as shown in Figure 4. The results are summarized in Table I. The particle sizes of poly(GEMA-co-St) microspheres were much smaller than those of poly $(\mathrm{St})$ microspheres $(f=0)$. This difference in the diameter may be due to that in the solubility. The addition of GEMA causes an increase in the solubility of St and, the particle diameter depends on the generation of charged stable oligomeric radicals which are converted to primary growing radicals. This was found for the copolymer microspheres of St and sodium styrene sulfonate. ${ }^{23}$ On the other hand, comparing the diameters calculated from SEM with those obtained from particle size distribution, the former samples have slightly smaller diameter than the latter. Akashi group ${ }^{18}$ reported that the copolymer comprised GEMA and $N, N^{\prime}$-methylenebisacrylamide forms a hydrogel and nonionic gels absorbed 30 times as much as water as their own weight. It is, therefore, considered that poly(GEMA- $c o-\mathrm{St}$ ) microspheres also form a hydrogel structures due to the GEMA moiety.

\section{XPS Measurement of Particles}

The surface of poly(GEMA-co-St) microspheres was analyzed quantitatively by XPS. The signals of $\mathrm{C}_{1 \mathrm{~s}}$ and $\mathrm{O}_{1 \mathrm{~s}}$ of poly(GEMA-co$\mathrm{St}$ ) microspheres with $f=10$ as a typical instance are illustrated in Figure 5. The $C_{1 \mathrm{~s}}$ spectra of the polymer microspheres coincide in position with those of the GEMA/St copolymer films prepared by Nakamae et al. ${ }^{19}$ Taking into account the results in the literature, ${ }^{19}$ the carbon signals at 285 and $291 \mathrm{eV}$ are ascribable to the methylene group and the shake-up satellite attributable to the $\pi-\pi^{*}$ molecular orbital transition of the benzene ring. The signals at 287 and $289 \mathrm{eV}$ are assigned to the $\mathrm{C}-\mathrm{O}-$ and $\mathrm{C}=\mathrm{O}$ originated from the GEMA moiety. The oxygen signal was observed at $533 \mathrm{eV}$. From the ratio of the number of atoms of oxygen to carbon $(\mathrm{O} / \mathrm{C})$ calculated from the $\mathrm{C}_{1 \mathrm{~s}}$ and $\mathrm{O}_{1 \mathrm{~s}}$, the GEMA 
Polystyrene Microspheres Surface-Modified with Glucoside Moieties
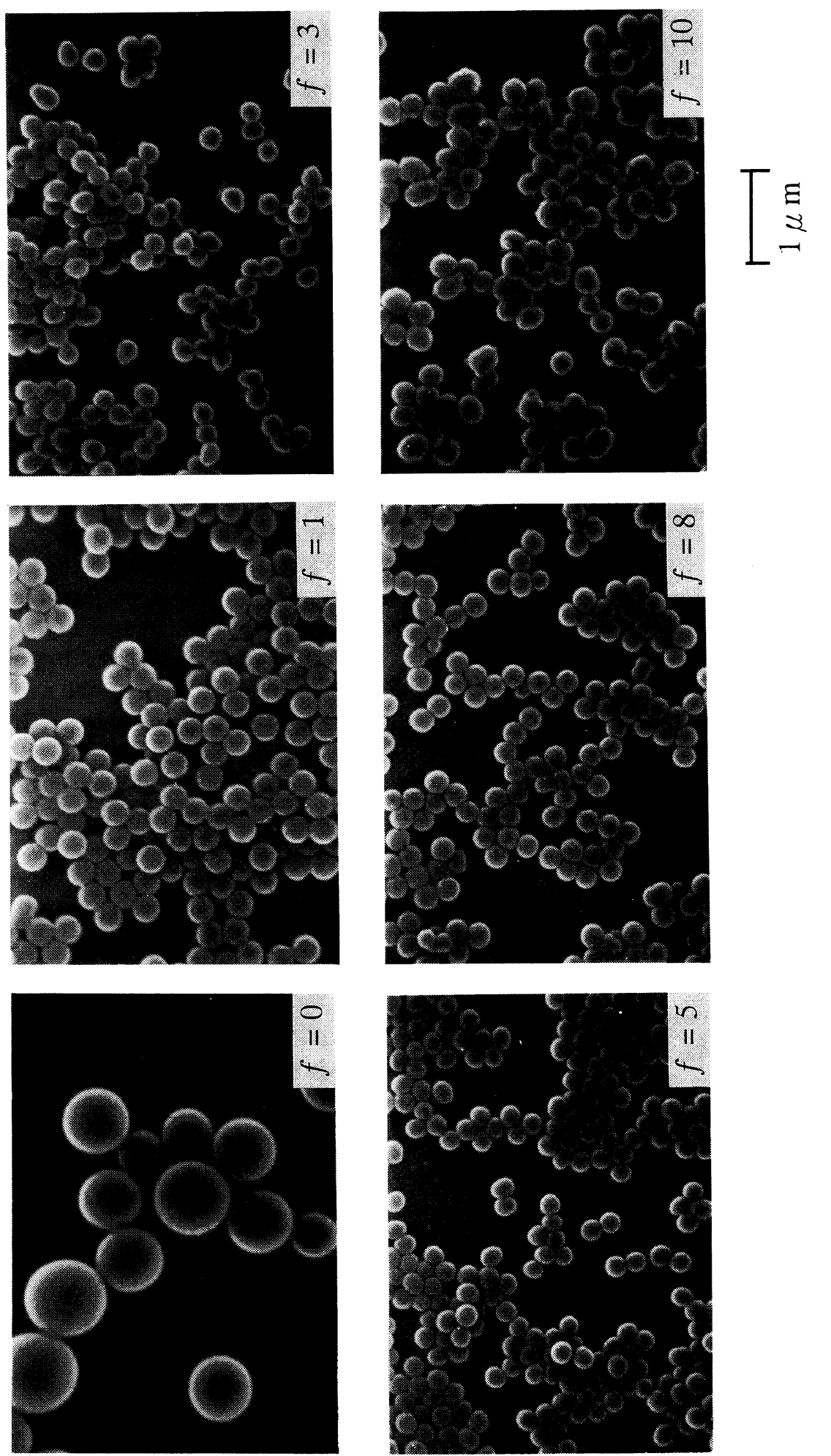

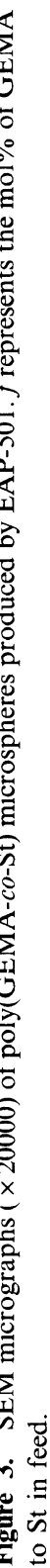



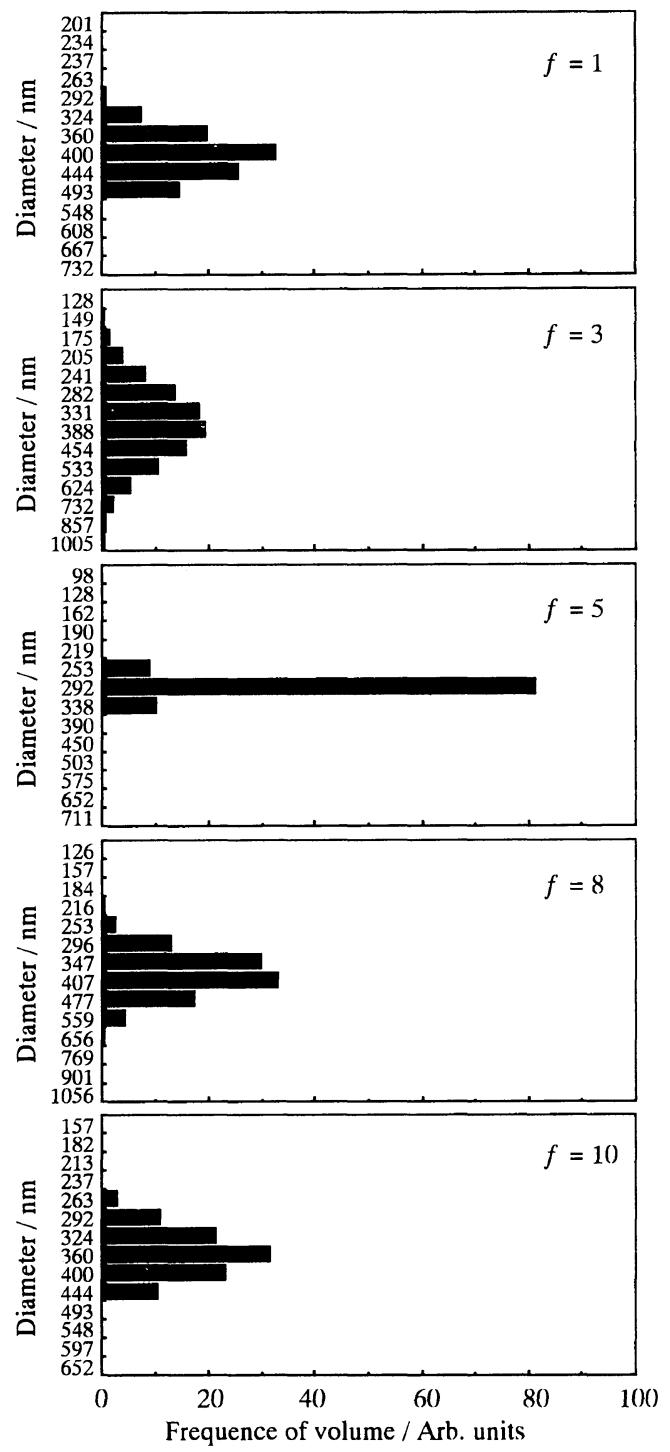

Figure 4. Particle size distribution of poly(GEMA-co-St) microspheres produced by EAP-501. $f$ represents the mol\% of GEMA to St in feed.

moiety is concentrated on the surface of the particles. The ratio of $\mathrm{O} / \mathrm{C}$ is calculated in Table $\mathrm{I}$, together with that of $\mathrm{O} / \mathrm{C}$ as calculated from the feed and elementary analysis. The ratio of $\mathrm{O} / \mathrm{C}$ obtained from XPS analysis was larger than that from elementary analysis except for the case of run 7. This means that the GEMA moiety is mainly located on the surface of the particles, rather than in bulk. Nakamae et al. reported that when copolymer films composed of GEMA and St were immersed in hot water, the surface became more hydrophilic because the GEMA unit migrated to the surface in order to minimize the surface free energy of the copolymer films. ${ }^{19}$ The content of the GEMA moiety located on the surface of particles is, therefore, considered to be much larger in the emulsion than that of content measured by XPS for the air-dried particles. The monomer reactivity ratios, $r_{1}$ and $r_{2}$, obtained by the free radical copolymerization of GEMA $\left(M_{1}\right)$ and St $\left(M_{2}\right)$ in DMF are 1.49 and $0.11^{24}$ (or 1.50 and $0.50^{19}$ ), respectively. The values of $r_{1}$ and $r_{2}$ indicate that the GEMA unit forms a block-like sequence in the copolymer. ${ }^{19}$ Hence, the GEMA sequence in poly(GEMA-co-St) microspheres in water is suggested to protrude from the surface of the particles.

No XPS signals of $\mathrm{N}_{1 \mathrm{~s}}$ and $\mathrm{P}_{2 \mathrm{p}}$ originating from the fragment of EAP-501 was found in poly(GEMA-co-St) microspheres. In the case of poly(St) microspheres produced by EAP501 as an initiator, it was confirmed from XPS that the zwitterionic initiating species are located on the surface of poly(St) microspheres. ${ }^{11}$ The signals for $\mathrm{N}_{1 \mathrm{~s}}$ at 402.5 and $400.0 \mathrm{eV}$ were assigned to the cyano group and the quarternary nitrogen and the signal for $\mathbf{P}_{2 p}$ at $134.0 \mathrm{eV}$ was assigned to the phosphate anion of the EAP-501 fragment. In the case of poly(GEMA-co-St) microspheres, it is believed that zwitterionic species are concealed behind the hydrophilic GEMA sequence on the located on the surface of the particles.

\section{$\zeta$-Potential Measurements of Particles}

The $\zeta$-potential of the polymer microspheres was measured at pH 5.6 at ambient temperature as tabulated in Table I. Poly(GEMA-co$\mathrm{St}$ ) microspheres produced by KPS have large negative charges due to the initiator fragment. Negative values of $\zeta$-potentials $(-\zeta)$ for poly(GEMA-co-St) microspheres are smaller than those for poly(St) styrene microspheres 
Table I. Preparation and characterization of poly(GEMA-co-St) microspheres ${ }^{\mathrm{a}}$

\begin{tabular}{|c|c|c|c|c|c|c|c|c|c|c|c|}
\hline \multirow{4}{*}{ Run - } & \multirow{4}{*}{$\frac{\text { GEMA }}{\mathrm{mmol}}$} & \multirow{4}{*}{$f^{\mathrm{b}}$} & \multirow{4}{*}{ Initiator } & \multirow{4}{*}{$\frac{Y_{\text {micro }} \mathrm{c}}{\%}$} & \multirow{4}{*}{$\frac{Y_{\text {coagu }}{ }^{c}}{\%}$} & \multicolumn{2}{|c|}{ Diameter $^{\mathrm{d}}$} & \multirow{2}{*}{\multicolumn{3}{|c|}{$10^{2} \cdot \mathrm{O} / \mathrm{C}^{\mathrm{e}}$}} & \multirow{4}{*}{$\frac{\zeta \text {-Potential }}{\mathrm{f}}$} \\
\hline & & & & & & \multirow{3}{*}{$\frac{\mathrm{SEM}}{\mathrm{nm}}$} & \multirow{3}{*}{$\frac{\mathrm{SD}}{\mathrm{nm}}$} & & & & \\
\hline & & & & & & & & \multirow{2}{*}{ Calc. } & \multirow{2}{*}{ EA } & \multirow{2}{*}{ XPS } & \\
\hline & & & & & & & & & & & \\
\hline 1 & - & 0 & EAP-501 & 74.9 & 5.8 & $590 \pm 80$ & - & - & - & - & 0 \\
\hline 2 & 2.4 & 1 & & 82.0 & 2.1 & $360 \pm 10$ & $392 \pm 49$ & 0.99 & 0.49 & 0.76 & -9 \\
\hline 3 & 7.2 & 3 & & 80.9 & 2.2 & $310 \pm 30$ & $353 \pm 83$ & 2.87 & 0.84 & 1.03 & -8 \\
\hline 4 & 12.0 & 5 & & 76.2 & 4.7 & $290 \pm 10$ & $290 \pm 20$ & 4.65 & 1.10 & 1.62 & -6 \\
\hline 5 & 19.2 & 8 & & 72.8 & 4.1 & $320 \pm 20$ & $353 \pm 65$ & 7.14 & 1.47 & 2.34 & -5 \\
\hline 6 & 24.0 & 10 & & 78.0 & 9.0 & $330 \pm 30$ & $342 \pm 46$ & 8.70 & 3.58 & 3.97 & -5 \\
\hline 7 & $24.0^{\mathrm{g}}$ & 50 & & 79.6 & $(15.0)^{\mathrm{h}}$ & - & - & 28.57 & 18.54 & 10.23 & 0 \\
\hline 8 & - & 0 & KPS & 93.4 & 1.6 & $840 \pm 100$ & - & - & - & - & -99 \\
\hline 9 & 2.4 & 1 & & 75.1 & 13.5 & $440 \pm 10$ & - & 0.99 & 0.07 & 0.88 & -70 \\
\hline 10 & 7.2 & 3 & & 67.1 & 12.4 & $240 \pm 20$ & - & 2.87 & 1.22 & 2.71 & -73 \\
\hline 11 & 12.0 & 5 & & 79.7 & 9.0 & $250 \pm 10$ & - & 4.65 & 2.99 & 4.18 & -68 \\
\hline
\end{tabular}

a St, $240 \mathrm{mmol}$; GEMA, varied; initiator, $0.25 \mathrm{mmol}$; water, $0.25 \mathrm{dm}^{3}$; speed of agitation, $350 \mathrm{rpm}$, at $70^{\circ} \mathrm{C}$ for $12 \mathrm{~h}$.

b $f$ represents $\mathrm{mol} \%$ of GEMA to St.

c $\mathrm{Y}_{\text {micro }}$ and $\mathrm{Y}_{\text {coagu }}$ represent the yields of polymer microspheres and coagulum, respectively.

d SEM and SD represent the diameter calculated by comparing SEM micrographs with polystyrene latex standard and that obtained from size distribution of particles, respectively.

e Calc, EA, and XPS represent the ratios of O/C calculated from feed, elementary analysis and XPS signals, respectively.

f Measured at pH 5.6 at ambient temperature.

g St, $48 \mathrm{mmol} ; \mathrm{H}_{2} \mathrm{O}, 0.15 \mathrm{dm}^{3}$; EAP- $501,0.13 \mathrm{mmol}$.

h Value in parentheses is the yield of water soluble polymer.
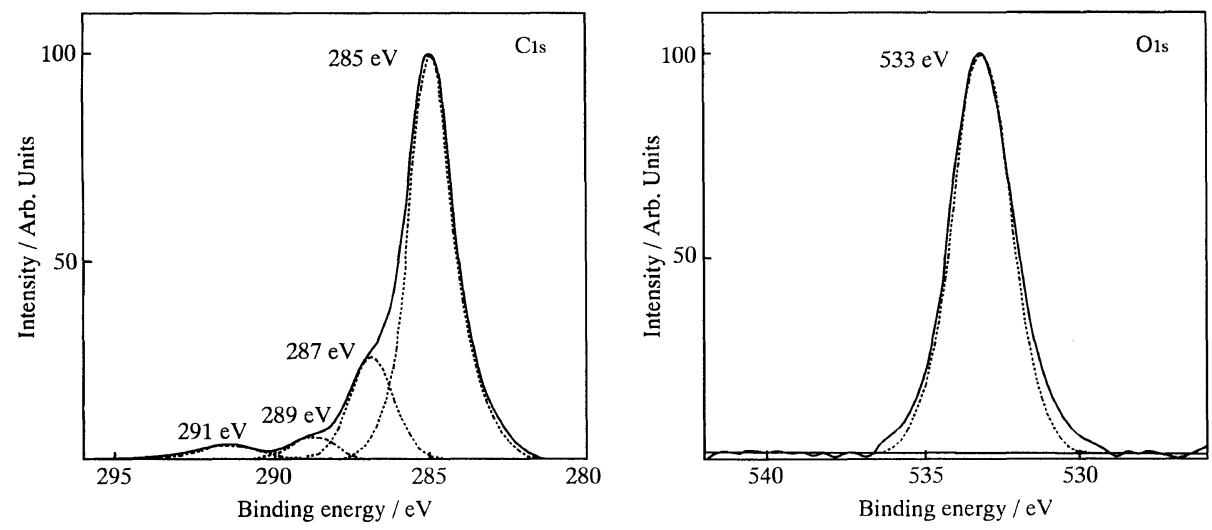

Figure 5. For $\mathrm{C}_{1 \mathrm{~s}}$ and $\mathrm{O}_{1 \mathrm{~s}}$ XPS spectra of poly(GEMA-co-St) microspheres $(f=10)$ produced by EAP-501.

$(f=0)$ and the decrease in $-\zeta$ is noted with increasing the ratio of $\mathrm{O} / \mathrm{C}$ obtained from XPS analysis. This phenomena was found in the poly(St)-poly(2-hydroxyethyl methacrylate)
(PHEMA) copolymer latices prepared by the seed polymerization. The decrease in $-\zeta$ is proportional to the content of HEMA in copolymers. ${ }^{25}$ These results are attributed to 
A :

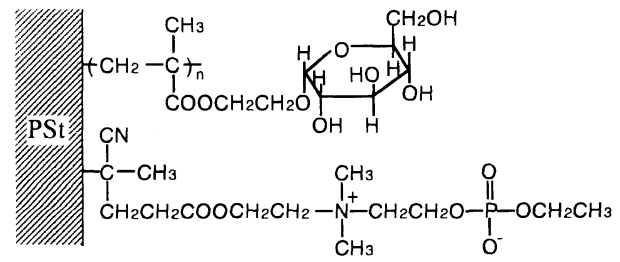

B :

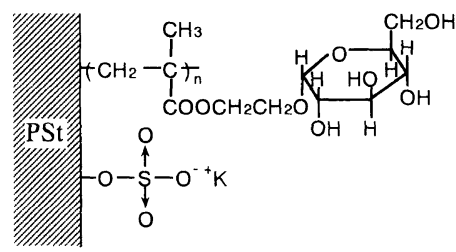

Figure 6. Schematic representation of the surface of poly(GEMA-co-St) microspheres produced by EAP-501 (A) and those produced by KPS (B).

the structure of the electrical double layer of these latices. $^{25}$ On the other hand, the $\zeta$ potential of the polymer microspheres produced by EAP-501 was nearly zero $(0 \sim-9)$ because the zwitterionic EAP-501 fragment was localized on the surface of the particles. The surfaces of the polymer microspheres in the emulsion were thus drawn based on the results of XPS and $\zeta$-potential measurements as shown in Figure 6.

\section{Protein Adsorption onto Poly(GEMA-co-St) Microspheres}

Since polymer microspheres have advantages such as extremely large surface area, and controlled surface charge density, the protein adsorption was studied using various lattices as adsorbents. ${ }^{25-27}$ The authors have also reported the adsorption of $\mathrm{Alb}$ onto various polymer microspheres. ${ }^{9-11,20,21}$

Interactions between poly(GEMA-co-St) microspheres modified with the glucoside moiety and the water soluble proteins such as Alb and Glo were studied to obtain basic data for biomedical application. Adsorption experiments were carried out at ionic strength 0.01 adjusted with $\mathrm{NaCl}$ aqueous solution at $\mathrm{pH} 5.6$ for $\mathrm{Alb}$. This $\mathrm{pH}$ is close to the isoelectric point of $\mathrm{Alb}$, whose molecules form a compact

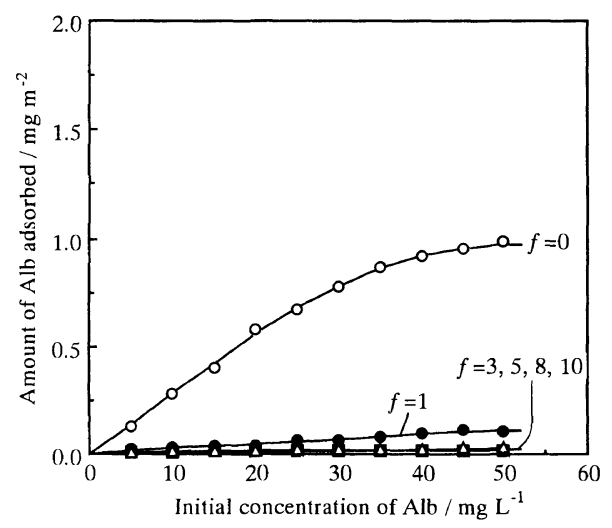

Figure 7. Effects of $f$ on the Alb adsorption onto poly(GEMA-co-St) microspheres produced by EAP-501, $\mathrm{pH}$ 5.6, ionic strength 0.01 , at $25^{\circ} \mathrm{C}$ for $2 \mathrm{~h}$. $f$ represents the mol\% of GEMA to St in feed.

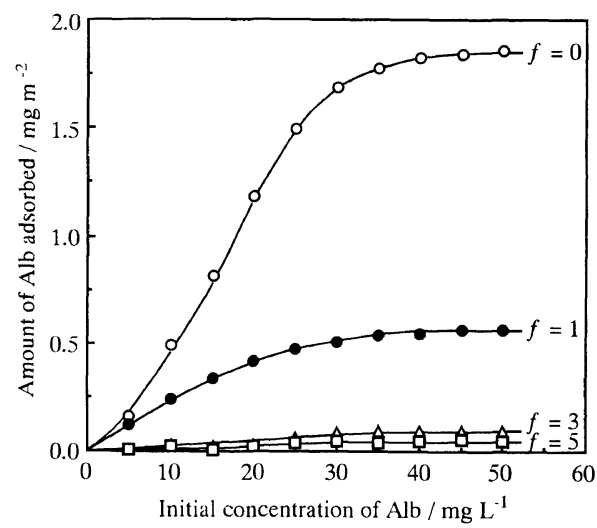

Figure 8. Effects of $f$ on the Alb adsorption onto poly(GEMA-co-St) microspheres produced by KPS, pH 5.6, ionic strength 0.01 , at $25^{\circ} \mathrm{C}$ for $2 \mathrm{~h}$. $f$ represents the $\mathrm{mol} \%$ of GEMA to $\mathrm{St}$ in feed.

structure. Figures 7 and 8 show results of the Alb adsorption onto poly(GEMA-co-St) microspheres $(f=1-10)$ produced by EAP-501 and $\mathrm{Alb}$ adsorption onto those $(f=1-5)$ produced by KPS, respectively, together with adsorption onto poly $(\mathrm{St})$ microspheres $(f=0)$ as the control. Two series of poly(GEMA-co$\mathrm{St}$ ) microspheres were found to adsorb Alb less than the control $(f=0)$. The amount of Alb adsorbed drastically decreased with increase in the ratio of $\mathrm{O} / \mathrm{C}$ due to the GEMA moiety. It is worthwhile to suppress Alb adsorption onto 


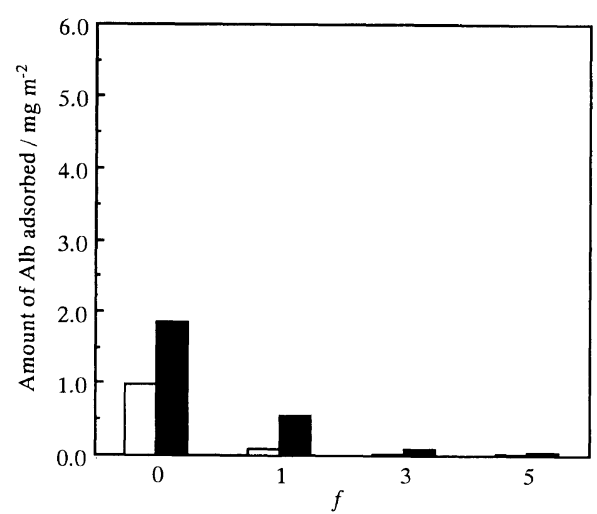

Figure 9. Effects of the initiating species on the adsorption of Alb onto poly(GEMA-co-St) microspheres, initial concentration of Alb $50 \mathrm{mgl}^{-1}$, ionic strength $0.01, \mathrm{pH}$ 5.6 at $25^{\circ} \mathrm{C}$ for $2 \mathrm{~h}$. $\square$, poly(GEMA-co-St) microspheres produced by EAP-501; $\square$, poly(GEMA-co-St) microspheres produced by KPS.

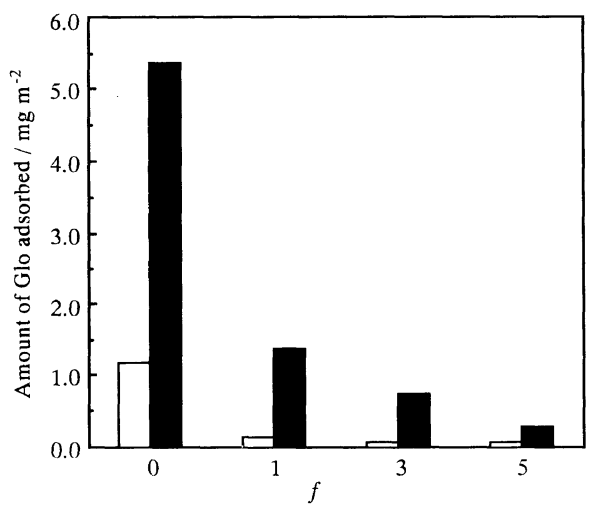

Figure 10. Effects of the initiating species on the adsorption of Glo onto poly(GEMA-co-St) microspheres, initial concentration of Glo $50 \mathrm{mgl}^{-1}$, ionic strength $0.01, \mathrm{pH}$ 6.7 at $25^{\circ} \mathrm{C}$ for $2 \mathrm{~h}$. $\square$, poly(GEMA-co-St) microspheres produced by EAP-501; $\square$, poly(GEMA-co-St) microspheres produced by KPS.

the polymer microspheres covered with ammonium phosphate groups less than Alb adsorption onto those covered with the fragments of KPS.

Glo adsorption onto poly(GEMA-co-St) microspheres was also measured at $\mathrm{pH} 6.7$ in a similar manner as above. Figure 9 shows a comparison of the adsorption of $\mathrm{Alb}$ onto poly(GEMA-co-St) microspheres produced by
EAP-501 with the case of polymer microspheres produced by KPS at $50 \mathrm{mg}^{-1}$ of initial concentration of Alb. Figure 10 shows Glo adsorption. It can be said from these figures that Glo adsorption is suppressed in a similar manner as Alb adsorption onto the surface of the polymer microspheres modified with the GEMA moiety and the fragment of EAP-501. Hence, the introduction of a structure analogous to the polar head group of phospholipids into poly $(\mathrm{St})$ results in suppression of the protein adsorption, rather than that of KPS fragment. As mentioned above, since polymer microspheres produced by KPS have much larger surface charge than those produced by EAP-501, the difference in the amount of protein adsorbed is due to that in surface charge. It is known that the formation of a microphase-separated biphasic structure ${ }^{28,29}$ or hydrogel structure ${ }^{30}$ and reduction of a hydrophobic interaction toward the adsorption of protein onto the polymer surface 21,31 are desirable to suppress protein adsorption. Ishihara et al. reported that copolymers containing phosphorylcholine units absorb water well and become hydrogel structures an important to decrease in protein adsorption. ${ }^{8}$ The copolymers bearing the GEMA moiety also become hydrogels. ${ }^{18}$ Taking into account these results, the suppression in the protein adsorption onto poly(GEMA-co-St) microspheres obtained here is due to a hydrogel structure formed in the particles with an artificial surface similar to a biomembrane.

From the results of the emulsifier-free emulsion copolymerization of GEMA with St and the characterization of resulting poly(GEMA-co-St) microspheres, the following conclusion can be drawn:

1. The rate of polymerization of $\mathrm{St}$ increases greatly in the presence of small amounts of GEMA at an earlier stage.

2. The copolymerization of GEMA and St gives poly(GEMA-co-St) microspheres with the sub-micron order of diameter in an adequate yield, accompanied by a small 
amount of coagulated polymers and water soluble polymer rich in the GEMA unit.

3. The GEMA moiety is mainly located on the surface of poly(GEMA-co-St) microspheres and the $\zeta$-potential is nearly zero for poly(GEMA-co-St) microspheres produced by EAP-501.

4. An artificial surface similar to a biomembrane is produced on particles by introducing the GEMA moiety and zwitterionic fragment of EAP-501.

5. Poly(GEMA-co-St) microspheres produced by EAP-501 suppressed effectively protein adsorption.

Acknowledgments. The authors thank Mr. T. Ohashi of Western Industrial Research Institute of Hiroshima for measurements of XPS. The authors are grateful to the Environmental Science Institute of Kinki University for financial support. This study was supported by a Grant-in-Aid for Scientific Research from Japan Private School Promotion Foundation.

\section{REFERENCES}

1. Z. Foltynowicz, K. Yamaguchi, B. Czajka, and S. L. Regen, Macromolecules, 18, 1394 (1985).

2. A. A. Durrani, J. A. Hayward, and D. Chapman, Biomaterials, 7, 121 (1986).

3. D. Letourneur, C. Donzon, and M. Jozefowicz, $J$. Polym. Sci., A, Polym. Chem., 29, 1367 (1991).

4. K. Yamaguchi, S. Watanabe, and S. Nakahara, Makromol. Chem., 190, 1195 (1989).

5. K. Ishihara, R. Aragaki, T. Ueda, A. Watanabe, and N. Nakabayashi, J. Biomed. Mater. Res., 24, 1069 (1990).

6. T. Ueda, K. Ishihara, and N. Nakabayashi, Kobunshi Ronbunshu, 48, 289 (1991).

7. K. Ishihara, N. P. Ziats, B. P. Tierney, N. Nakabayashi, and J. M. Anderson, J. Biomed. Mater. Res., 25, 1937 (1991).

8. T. Ueda, H. Oshida, K. Kurita, K. Ishihara, and N. Nakabayashi, Polym. J., 24, 1259 (1992).

9. K. Sugiyama and H. Aoki, Polym. J., 26, 561 (1994).
10. K. Sugiyama, K. Ohga, H. Aoki, and N. Amaya, Macromol. Chem. Phys., in press.

11. K. Sugiyama, K. Ohga, and K. Kikukawa, Macromol. Chem. Phys., 195, 1341 (1994).

12. P. H. Weigel, R. L. Schnaar, S. Roseman, and Y. C. Lee, Methods Enzymol., 83, 294 (1982).

13. K. Kobayashi, H. Sumitomo, and Y. Ina, Polym. J., 17, 567 (1985).

14. A. Kobayashi, T. Akaike, K. Kobayashi, and H. Sumitomo, Makromol. Chem. Rapid Commun., 7, 645 (1986).

15. K. Kobayashi, H. Sumitomo, A. Kobayashi, and T. Akaike, J. Macromol. Sci. Chem., A25, 655 (1988).

16. T. Akaike, A. Kobayashi, K. Kobayashi, and H. Sumitomo, J. Bioact. Compat. Polym., 4, 51 (1989).

17. S. Kitazawa, M. Okumura, K. Kinomura, and T. Sakakibara, Chem. Lett., 1733 (1990).

18. N. Fukudome, K. Suzuki, E. Yashima, and M. Akashi, J. Appl. Polym. Sci., 52, 1759 (1994).

19. K. Nakamae, T. Miyata, N. Ootsuki, M. Okumura, and K. Kinomura, Macromol. Chem. Phys., 195, 2663 (1994).

20. K. Sugiyama, K. Shiraishi, K. Ohga, H. Shirahama, H. Tamai, H. Yasuda, and K. Kikukawa, Polym. J., 25, 521 (1993).

21. K. Sugiyama, H. Nakano, and K. Ohga, Macromol. Chem. Phys., in press.

22. O. H. Lowry, N. J. Rosebrough, A. L. Farr, and R. J. Randall, J. Biol. Chem., 193, 265 (1951).

23. J. H. Kim, M. Chainey, M. S. El-Asser, and J. W. Vanderhoff, J. Polym. Sci., A, Polym. Chem., 30, 171 (1992).

24. K. Kinomura, S. Yamamoto, S. Kitazawa, M. Okumura, and T. Sakakibara, Chem. Express, 7, 793 (1992).

25. H. Shirahama and T. Suzawa, J. Colloid Interface Sci., 104, 416 (1985).

26. T. Suzawa, H. Shirahama, and T. Fujimoto, J. Colloid Interface Sci., 86, 144 (1982).

27. H. Shirahama, H. Ohno, and T. Suzawa, Colloid and Surf., 60, 1 (1991).

28. N. Yui, K. Sanui, N. Ogata, K. Kataoka, T. Okano, and Y. Sakurai, J. Biomed. Mater. Res., 20, 929 (1986).

29. A. Hirao, H. Kato, K. Yamaguchi, and S. Nakahama, Macromolecules, 19, 1294 (1986).

30. Y. Ikada, H. Iwata, F. Horii, T. Matsunaga, M. Taniguchi, M. Suzuki, W. Taki, S. Yamagata, Y. Yonekawa, and H. Handa, J. Biomed. Mater. Res., 15, 697 (1981).

31. K. Ishihara, N. Negishi, and I. Shinohara, J. Appl. Polym. Sci., 27, 1897 (1982). 